\title{
Preparing for Critical Infrastructure Breakdowns: The Limits of Crisis Management and the Need for Resilience
}

\section{Arjen Boin* and Allan McConnell**}

\author{
*Leiden University Crisis Research Center, Department of Public Administration, PO Box 9555, 2300 RB \\ Leiden, The Netherlands. E-mail: boin@fsw.leidenuniv.nl \\ **Discipline of Government and International Relations, University of Sydney, NSW 2006, Australia. E-mail: \\ a.mcconnell@econ.usyd.edu.au
}

\begin{abstract}
Modern societies are widely considered to harbour an increased propensity for breakdowns of their critical infrastructure $(\mathrm{Cl})$ systems. While such breakdowns have proven rather rare, Hurricane Katrina has demonstrated the catastrophic consequences of such breakdowns. This article explores how public authorities can effectively prepare to cope with these rare events. Drawing from the literature on crisis and disaster management, we examine the strengths and weaknesses of traditional approaches to crisis preparation and crisis response. We argue that the established ways of organising for critical decisionmaking will not suffice in the case of a catastrophic breakdown. In the immediate aftermath of such a breakdown, an effective response will depend on the adaptive behaviour of citizens, front-line workers and middle managers. In this article, we formulate a set of strategies that enhance societal resilience and identify the strong barriers to their implementation.
\end{abstract}

\section{Introduction: Imagining the Consequences of Infrastructural Breakdown}

M odern society relies on the effective functioning of $\mathrm{Cl}$ networks to provide public services, enhance quality of life, sustain private profits and spur economic growth. This growing dependence is accompanied by an increased sense of vulnerability to new and future threats such as terrorism and climate change (OECD, 2003; Perrow, 2006). With some urgency, the question is being asked - in Australia, Europe and the United States - how modern societies can prepare for a breakdown in Cls.

Definitions of $\mathrm{Cl}$ vary widely, ranging from hardware such as cables and wires, through to networks for the generation and supply of energy sources, food supplies and public order.' The degree of criticality is bound to differ across systems and cultures (see Egan, this issue), but it is widely thought that a breakdown of one or more of these critical systems has the potential to cause very serious problems.

We know relatively little about the causes of infrastructural breakdown. It is commonly agreed that complexity and tight coupling allow relatively small disturbances to rapidly escalate into compound crises (Turner, 1978; Perrow, 1999). And as Cls become increasingly massive and complex (due to scale requirements) as well as dependent on other $\mathrm{Cls}$, there is an increasing likelihood of multiple infrastructural breakdowns that reach beyond geographical and functional borders (Rosenthal, Boin and Comfort, 
200I; Quarantelli, Lagadec and Boin, 2006). Yet, it remains unclear at best under which conditions these systems actually break down and what engineers can do to prevent breakdowns from happening (LaPorte, 1996; Baer et al., 2005). Worst-case scenarios do not always take into account the adaptive behaviour of system managers (the $\mathrm{Y} 2 \mathrm{~K}$ scare comes to mind).

The most complicating factor, however, is that we cannot predict with any degree of precision the potential consequences of infrastructural failure. Relatively few major infrastructural failures have actually occurred in Western societies. Most of these were single breakdowns (grid failures in the US, Canada, France and New Zealand). While these breakdowns were not without consequences (Scanlon, 1999; Newlove, Stern and Svedin, 2000; Lagadec and Bertone, 2003), they do not approximate the level of affliction envisioned to be the result of compound failures - when multiple infrastructures break down more or less simultaneously. This happened when Hurricane Katrina wiped out most if not all Cls for a considerable amount of time in New Orleans and large parts of Louisiana and Mississippi, which effectively crippled recovery operations both in the short and long term.

The aim of this article is to peruse the crisis and disaster management literature to formulate lessons that may enhance societal preparation for such breakdowns. This body of research suggests that conventional prevention and contingency planning approaches, as well as traditional top-down crisis management responses, have major limitations in the face of critical infrastructural breakdowns. Given these lessons, our contention is that public authorities should focus on the long-term promotion of societal resilience.

We set out by relating critical infrastructural breakdowns to key concepts in the crisis and disaster literature. We then identify the key lessons of this research and formulate practical steps towards furthering societal and administrative resilience. We are realistic in recognising that there are significant barriers to a rapid upgrading of societal resilience capacities. We conclude this article by identifying pressing research needs.

\section{Cl Breakdowns: Rare Events with Catastrophic Potential}

In wealthy and well-functioning societies, it has become hard to imagine what happens - or fails to happen when nothing works. What does it mean to reside in a society that is suddenly beset by multiple and cascading failures, power blackouts, transport gridlocks, telecommunications breakdowns, overwhelmed emergency services and civil disorder? Most habitants of Europe, Australia and North America probably have no idea.

The chaos and disorder that overtook New Orleans in the wake of Hurricane Katrina (August 2005) provide us with some clear ideas of what a worst-case scenario may look like. Yet, $\mathrm{Cl}$ breakdowns are not necessarily accompanied by the deadly mayhem witnessed in New Orleans and its surrounding areas. Some breakdowns remain isolated events and are quickly remedied, others have cascading effects and cause great harm. These breakdowns can range from mere emergencies to fullblown catastrophes. Let us briefly consider how this sliding scale of threat relates to key concepts in the literature on crisis, disaster and emergency management.

Emergencies are 'unforeseen but predictable, narrowscope incidents that regularly occur' (Perry and Lindell, 2006: 29). These events are delineated in time and space. As they are knowable and follow fairly predictable patterns, emergency services can train and prepare for these events. Emergencies can be tragedies for those involved, but have no wider consequences and can usually be brought rapidly to a closure. Examples include the blocking of a main highway by a chemical spillage, or a small radiation leakage at a nuclear power plant.

Crises are of a different magnitude and character. A crisis may be defined as 'a breakdown of familiar symbolic frameworks that legitimises the pre-existing socio-political order' ('t Hart, 1993: 39). It entails a threat to the core values of a system or the functioning of life-sustaining systems, which must be urgently dealt with under conditions of deep uncertainty (Rosenthal, Boin and Comfort, 200I). Cl breakdowns that depart from known failure paths and 'behave' in seemingly erratic ways, jumping from one system to another, tend to generate a deeply felt sense of crisis. The breakdown of the electrical grid across the north-eastern US (2003) caused more than just an emergency; it constituted a real crisis - broadcast live on the major networks - and posed operational and strategic challenges to both governmental and private actors.

But the 2003 blackout hardly qualifies as a disaster. This is, of course, yet another contested term (Perry and Quarantelli, 2005), but it tends not to be used in reference to extreme situations where life, property and infrastructure remain intact. To label a situation in terms of disaster implies loss of life and severe, longterm damage to property and infrastructures. A disaster, in other words, is a 'crisis with a bad ending' (Boin, 2005: 163). Cl breakdowns easily generate a sense of crisis, but, it is fair to conclude, rarely result in disaster (see for example the 1998 Sydney water contamination crisis: Healy, 200 I; McConnell, 2005).

Some disasters are clearly in a league of their own: we refer to these as catastrophes. In some respects, the difference between a disaster and a catastrophe is 
merely semantic. Moreover, it is affected by cultural dispositions (what is a disaster in one country may be perceived as catastrophic in others). Nevertheless, catastrophes are at the furthest end of the scale in terms of the language we use to describe threatening events and their (potential) consequences. A catastrophe is defined as an 'event that is believed to have a very low probability of materializing but ... if it does materialize will produce a harm so great and sudden as to seem discontinuous with the flow of events that preceded it' (Posner, 2004: 6).

Some agents of catastrophe - think of asteroids and super volcanoes - are unlikely to materialise in our life spans, but we cannot rule out their occurrence (Clarke, 2005). However unlikely, a catastrophe can happen any day, as demonstrated by the Asian tsunami and the destruction of New Orleans by Hurricane Katrina.

The question is whether infrastructural breakdowns can cause unprecedented damage (in terms of property and lives lost), paralysing life-sustaining functions for long periods of time. Many scenarios have seen the light (with a notable spike during the pre-Millennium months), but catastrophes caused by infrastructural breakdowns have yet to emerge. They fall in the category of 'future crises' (Rosenthal, Boin and Comfort, 200I) and 'worst cases' (Clarke, 2005). Discussing $\mathrm{Cl}$ breakdowns in terms of potential catastrophes is, therefore, somewhat of a theoretical exercise.

Yet, mapping out the sheer devastation and chaos that may ensue, we get a real sense that an infrastructural breakdown may present challenges that are well beyond the routine contingency planning and management capacities of public authorities. If we have serious aspirations to deal with the consequences of these future crises, we need to identify both the weaknesses of traditional crisis and disaster management practices, as well as the seeds of a strategy for enhancing our capacities to cope with worst-case scenarios.

\section{The Limitations of Prevention, Planning and Traditional Top-Down Crisis Management}

The overwhelming tendency in both theory and practice is to view crisis management as a holistic process involving prevention, planning, acute response, recovery and learning (Comfort, 1988; Nudell and Antokol, 1988; Coombs, 1999; Fink, 2002; Regester and Larkin, 2002; Curtin, Hayman and Husein, 2005). In this section, we consider whether traditional crisis management approaches and practices are likely to be effective in the case of an infrastructural breakdown with catastrophic consequences.

\section{Prevention and its limits}

There are many successful instances of crisis prevention. For instance, the Dutch have built an elaborate defence system against the catastrophic potential of the North Sea. The segregation and destruction of birds harbouring the $\mathrm{H} 5 \mathrm{NI}$ bid flu virus has proved reasonably successful in preventing the spread of the disease to Western Europe and the Americas. The American and British Governments have foiled several major terror plots aimed at transatlantic flights, Heathrow Airport and the Brooklyn Bridge. More in general, we can observe that many types of disasters no longer, or rarely, occur in modern societies that used to be commonplace (think of bridge disasters, theatre fires and polio outbreaks).

We should, however, temper our expectations. Preventing all extreme threats from materialising is not only implausible, it is simply impossible (cf. Wildavsky, 1988). We cannot know every conceivable 'worst case' that may unfold. Terrorists can become inventive beyond our imagining. The 2004 Boxing Day tsunami reminded us of nature's power to produce swift devastation. Prevention requires that one knows the source and dynamics of threats, but the literature shows that this is impossible for most if not all organisations (Turner, 1978; Reason 1990, 1997; Pauchant and Mitroff, 1992; Anheier, 1999; Gauld and Goldfinch, 2006).

Preventing threats can also meet with political repercussions because prevention strategies can damage powerful interests (Drennan and McConnell, 2007). The BSE crisis in the UK is indicative of this phenomenon. A powerful agricultural lobby was instrumental in building alliances with ministers and risk-averse civil servants in order to thwart demands from leading scientists that more needed to be done to recognise and prevent the possibility of transmission to humans (Phillips Inquiry, 2000; Beck, Asenova and Dickson, 2005).

While there is ongoing debate between 'normal accident' theorists and their 'high reliability' counterparts (JCCM, 1994; Rijpma, 1997; Perrow, 1999; Weick and Sutcliffe, 2002) about the capacity of organisational reforms to reduce the propensity for 'internally' induced significant failures, these authors seem to agree that it is impossible to eliminate all errors or suppress every deliberate act of destruction. In short, the lessons of crisis management research hold that there are political, cognitive, informational, cultural and resource barriers to being able to prevent every possible threat to our Cls.

\section{Contingency planning: necessary but not sufficient}

Planning for emergencies and crises is to be lauded. There is much to be gained from the prior specification 
of roles and responsibilities; the allocation of materials, equipment and information systems; and the testing of systems under 'trial' conditions through simulations and exercises (Rosenthal and Pijnenburg, 199I; 't Hart, 1997; Boin, Kofman and Overdijk, 2004). For example, the city of Madrid was able to resume normal operations only twenty-four hours after the 2004 bombings (Cornall, 2005); Australian authorities responded effectively to the 2002 Bali Bombings (Paul, 2005), and the response to the $9 / 1$ I attacks by New York's emergency services worked reasonably well because of long-established planning and exercises (National Commission on Terrorist Attacks upon the United States, 2004).

Planning is no panacea, however (McConnell and Drennan, 2006). In fact, planning for crisis is almost a contradiction in terms. How can we plan for a phenomenon that, by its very nature, violates the very regular patterns upon which planners rely in order to prevent it? Indeed, the range of potential crisis and disaster triggers that we may plan for (ranging from tsunamis and hurricanes through to plane crashes and terrorist attacks) constantly expands as we discover new and potent threats. Developing plans that work for the endless array of complex, chaotic and destructive scenarios that arise from interlocking and often mutually dependent infrastructures may be all but impossible.

The planning process itself has some in-built vulnerabilities. For instance, planning requires multi-agency cooperation and coordination (Hillyard, 2000), which often strand in the realities of bureaucratic politics (Rosenthal, 't Hart and Kouzmin, 1991). The barriers to cross-agency collaboration include differences in organisational goals, professional cultures, lines of accountability, political control styles and decision-making cycles. To complicate matters, many of the organisations involved in crisis planning involve actors in the voluntary and private sectors. In the case of Cls, it should be realised that vast networks of formerly public utilities are wholly or partly in the hands of privatised or semi-privatised companies (cf. Boin and Smith, 2006).

Then there is the matter of costs. The conversion of 'paper plans' into organisational readiness through staff training and crisis exercises can be expensive and time consuming. Investing resources to plan for a multitude of extreme events that may never happen is no easy sell in a time of budget constraints. Other organisational factors such as cultural complacency, resource limitations and shifting priorities conspire to derail or deadend a crisis plan.

Hurricane Katrina is a clear example (Dyson, 2006; Select Bipartisan Committee, 2006). Despite a major exercise ('Hurricane Pam') in 2004, the response of local and state authorities proved insufficient at best. This planning failure was shaped by a combination of: (i) psychological pathologies on the part of public authorities (overvaluation, overconfidence, insensitivity and wishful thinking); (ii) bureaucratic complexity and conflict in the US federal system, and (iii) a post-9/II homeland security agenda that focused on terrorism (not natural hazards), leading to a trickle-down effect in terms of resource allocation and sub-federal institutional agendas (Parker, Stern and Paglia, 2006).

This failed planning for a major hurricane illustrates the wider argument by Clarke (1999) that contingency plans often amount to little more than 'fantasy documents'. In other words, they signal a state of preparedness that bears little relation or relevance to the challenges that emerge with a crisis. It would be unwise to completely disregard planning as a preparation tool for $\mathrm{Cl}$ breakdowns, but we should not be overconfident with regard to the capacity of a plan to prepare operational responders and crisis managers for the vast range of extraordinary, complex and critical threats that they are sure to encounter in times of crisis.

\section{Top-down responses in the acute phase: useful up to a point}

If crisis and disaster research teaches us that prevention and planning come with serious shortcomings, an alternative might be to put our faith in traditional top-down crisis management responses. After all, in times of extreme threats, power and authority tend to shift up hierarchies to converge in the hands of political leaders and chief executives ('t Hart, Rosenthal and Kouzmin, 1993). This 'centralisation reflex' can be defended on the grounds of expediency (authorising crucial measures and approving emergency resource allocation) and on the grounds of societal expectation. During a crisis, citizens, media representatives, lobby groups, public administrators and private organisations all look to government to make sense of what is going on and to 'do something' to restore order.

Even in the absence of hard and fast rules for judging successful coping patterns (McConnell, 2003), it is clear that leadership can prove a crucial factor in facilitating an effective operational response and managing (at the political-symbolic level) the fears and anxieties that typically accompany crises, disasters and catastrophes. Recent examples include Mayor Giuliani in the immediate aftermath of the $9 / 1 \mathrm{I}$ attacks and the German Chancellor Schröder after the 2002 Elbe floods.

Such instances may be the exception rather than the norm, however. In fact, we should not invest too much faith in the capacity of political leaders to 'deliver' in times of crisis. A crisis poses a complex set of challenges for public leaders at all levels of government (Boin et al., 2005). Leaders are liable to find themselves in a Catch 22 situation: they cannot make things happen (because compound failures manifest themselves at multiple organisational sites in a variety of geographical 
locations) while society looks to them - more than ever before - to somehow 'fix' the problems, and restore a sense of order and confidence in governmental structures.

Moreover, crisis leaders experience fierce constraints in their efforts to manage the response efforts. Reliable information about the situation or the state of the response network is often unavailable. Hard facts are difficult to come by and rumours abound. Continuing uncertainty feeds the rumour cycle, which deepens uncertainty. Communication typically fails (in the sense of technical breakdowns, but also in terms of distorted messages connecting leaders and citizens). Leaders and their inner circles suffer from increased stress, which feeds a common perception that the public is acting in irrational ways. The resulting 'disconnect' between leaders and citizens, in turn, feeds on itself. For example, when mayor Ragin described New Orleans as a living hell, people started behaving as if they lived in one (arming themselves and barricading themselves in make-shift forts). The overall result is undermined trust in the governmental capacities to deal with the crisis.

The media feeds the cycle. Failures make better journalistic copy than successes, and amidst crisis and catastrophe, there are plenty of opportunities to confront and judge political leaders (Sabato, 2000; Altheide, 2002). The media seek official reactions on reports that are often new to leaders. Failures to react quickly and adequately will further undermine the legitimacy of those in political office (and who are already tarnished by the crisis).

Some leaders may be better at coping with crisis and catastrophe than others (Flin, 1996; Hermann et al., 200I; Post, 2004). Yet, there are clear limitations to what we can reasonably expect from our political leaders in attempting to 'manage' the response to critical breakdowns. Traditional crisis management practices can prove highly beneficial and they certainly should not be abandoned. However, they will be found wanting in case of a disastrous or catastrophic breakdown. We can enhance administrative and societal capacities to cope under such conditions by introducing a complementary strategy: the promotion of resilience.

\section{Bridging the Gap: Promoting Societal Resilience}

The research on large-scale natural disasters strongly suggests that an effective response during the immediate aftermath (the first hours and days) critically depends on the resilience of citizens, first-line responders, and operational commanders (Barton, 1969; Dynes, 1970; Drabek, 1986). Only in the long-run (days, weeks, months) can strategic leaders make a tangible difference 'on the ground'. In preparing to deal with crises and, especially, catastrophes, efforts should therefore be focused on the promotion of resilience i.e. the ability to 'bounce back' after suffering a damaging blow (Wildavsky, 1988: 77; Baer et al., 2005; Longstaff, 2005).

In theoretical discourses on the subject, the capacity to recover quickly from a devastating blow is sometimes seen as an 'emerging property' of a 'healthy' system (Longstaff, 2005). While it seems rather obvious that societal health - measured in terms of resources, experience, institutional quality - would increase the chances of a speedy recovery, it should be remembered that theories of system failure and theories of resilience are, indeed, just that: theories. Suggesting a 'hands off approach would therefore seem overly optimistic. Rather, we need to consider what public leaders can and cannot do to create the conditions under which resilience is likely to emerge.

In the remainder of this article, we map out some potential strategies to promote societal resilience. These strategies should be considered part of an incremental, trial-and-error process towards enhancing societal resilience, which remain to be tested in future disasters and further research.

Before we discuss these strategies, it appears that the enhancement of societal resilience presupposes two necessary conditions. First, there must be a general awareness that a catastrophe may strike, paralysing normal governmental functions and Cls. If an 'it couldn't happen here mentality' exists, it needs to be challenged. It is true that, in the wake of recent terrorist attacks, thinking about threats has become increasingly 'normalised'. Yet, these debates are strongly focused on terrorism and highly politicised as a result.

It may be difficult to galvanise society to think about resilience unless people feel 'fear'. The challenge is to cultivate a climate in which people receive realistic assessments of potential risks, without creating undue stress and anxiety. Yet, risk management is an inexact science and is always subject to distortion and framing through political filters. ${ }^{2}$

Second, an investment in resilience should not replace a concern with the basic elements of any response operation. The following basic response mechanisms should be in place and work in a more or less autonomous fashion: warning; mobilisation; registration; evacuation; sheltering; emergency medical care and after care; search and rescue; protection of property and information dissemination. Every crisis and disaster uncovers serious shortcomings with regard to these basic functions.

\section{Strategies for enhanced societal resilience}

\section{Preparing first responders}

If an effective response to a catastrophic breakdown of $\mathrm{Cls}$ depends on the performance of the so-called first 
responders, these people must be identified and trained to act independently and effectively in dire circumstances. They must feel capable to operate 'in the dark' - to seize initiative (as command structures collapse) and perform their tasks. They should be instilled with a set of core values, ethics and priorities that will guide them in their decisions and actions. Potential responders should be trained to assess when plans need to be activated and adhered to and when plans are rendered useless (and therefore should be pitched). Knowing the difference between the two can prove exceptionally difficult but at least prior exposure to such issues enhances the capacities of individuals to make such judgments when the time has come.

\section{Business continuity planning}

An infrastructural breakdown typically has a devastating impact on local businesses (Tierney, 2006). As the recovery of local businesses is instrumental to societal resilience, they should be encouraged to develop a business continuity plan. Such a plan helps organisations think about setting up an emergency operations centre, an off-site location for 'mirror' operations, off-site IT back-up, and mobile information gathering units. They should also be encouraged to consider how they can play a role in the initial response to catastrophic breakdowns. In the immediate aftermath of Hurricane Katrina, Wal-Mart quickly and effectively used its logistical expertise to move goods into ravaged areas. The positive media coverage was, of course, a nice spinoff for a company under siege for alleged exploitation of its employees.

\section{Working with communities}

Contingency planning and business continuity plans should be conducted in full consultation with local communities (Coles and Buckle, 2004). To this end, partnerships should be developed (government, business, citizens, media) that facilitate an 'organic' community response to catastrophe. There is always the danger of consultation only with self-selecting and unrepresentative community members and of power inequalities between stakeholders, but there are (at the very least) symbolic benefits of engaging community stakeholders in this way. It may help enhance (if only to a small degree) a sense of ownership over plans.

\section{Working with private owners of $\mathrm{Cls}$}

In most western countries, a substantial part of the $\mathrm{Cl}$ landscape is directly or indirectly in private hands. This means that the repair of $\mathrm{Cl}$ breakdowns is, in many cases, a job for the operator or owner. Governments typically bear responsibility for the consequences of these breakdowns. The boundary between the two is not always clear, however. Private actors should get more incentives to invest in changing management structures, practices and cultures in order to anticipate, mitigate and plan for breakdowns and their societal consequences. Governmental actors should get to know these private actors who will become their counterparts during a crisis. Public and private actors should invest in an institutional venue for public-private collaboration that is driven neither by 'top down' government nor market forces.

\section{Joint preparation}

Planning and exercising for worst-case scenarios should be a continuous and joint activity that is valued for the process (not the outcome). An effective planning process is an intellectual effort to explore potential problems and invite possible solutions. The planning process should involve all potential partners in a given region. The continuous, comprehensive and ever-evolving nature of the planning process requires a permanent coordinating force, which creates the right conditions for such cooperation across functional and hierarchical boundaries.

\section{Joint training}

Public and private organisations should regularly expose their contingency and business continuity plans to simulations and exercises. Such trials may be 'in house' but they should also be complemented by regular multiagency exercises. Joint exercises build mutual trust and understanding, creating awareness with regard to each other's capacities. Exercises nurture personal relations that will be a vital resource for improvisation and collaboration.

\section{Training leaders}

Political and organisational leaders need to develop their capacity to facilitate resilient behaviour in times of crisis. As a first step, they must learn to avoid traditional leadership pathologies in crisis situations. These include: sticking with the plan; waiting for all facts and figures before making critical decisions; acting as if the command and control structure still stands; waiting for outside help; spreading unverified rumours; initiating the 'blame game'; berating the public (e.g. 'they should have evacuated') and treating the media as an enemy. They must understand that there is not much they can do during the initial phases of a critical breakdown that will make an immediate difference 'on the ground'. Leaders should have a realistic understanding of the limited range of tasks that do make a difference. They can facilitate a resilient response if they perform - or learn to perform - the following tasks before a disaster occurs:

- Create expert networks. Every catastrophe will require some form of expertise to inform critical decision-making. If leaders wait until a crisis materi- 
alises, they depend on the availability of experts. At that time, it is impossible to scrutinise the background and qualities of experts. Vetting experts and building trust relations can and should be done beforehand.

- Facilitate systems for the identification of capable partners. The management of extraordinary breakdowns requires improvisation and flexibility, not only with regard to activities but also with regard to actors. Key organisations may be paralysed and replacements may become necessary. Leaders should scan the public and private domains for potential partners, mapping capacities, locations, contact persons and contact details.

- Train for situational and information assessment. Leaders must learn to distinguish between the types of decisions that can reasonably be taken without the full 'facts' and those that need additional evidence before action can be taken; learn to assess what types of information are needed immediately and what will materialise in time; and learn to recognise and deal with rumours, speculation, ambiguity and information overload. Leaders must learn to quickly assess what still works, what has become impossible, and how available resources can be recombined to serve crucial functions.

- Learn how to support and facilitate emerging nodes of coordination. Emergency services and citizens tend to evolve informal nodes in which information streams come together and actors mutually adjust their response activities. These nodes typically develop in ways and places unforeseen in the disaster planning phase. Public leaders should learn to identify and support these emerging nodes.

- Organise outside forces. While it is hard if not impossible to direct the immediate response effort from afar, public leaders can mobilise outside assistance and coordinate their entry into the catastrophe area. This aid can be provided by the military, societal groups, NGOs, private businesses or international actors. Leaders should be prepared to work with these actors, even if they do not fit naturally in the standing plans or command-andcontrol structures.

- Working with the media to provide a crisis rationale. A crisis shatters our understanding and expectations of how the world works. Leaders are in a unique position to explain what is going on, how it came about, and where it is leading society. They can provide a 'frame' that anchors the thinking and actions of people on the ground, who are literally lost in the crisis. The narrative does not have to be 'true', it should be convincing and effective in providing a sense of direction and hope. In engaging in such 'meaning making' (Boin et al., 2005), leaders should learn how to work with the media, not against it. They must learn how the media works in times of crisis, what they should do and not do. In short, they must learn how to manage media without getting absorbed by it.

- Initiate long-term reconstruction. While strategic leaders cannot do all that much to provide immediate relief on the ground after a disaster or catastrophe strikes, they can do much more when it comes to the long-term recovery and reconstruction of the stricken region. This process of recovery will have to begin almost immediately. Leaders should create networks that can help identify partners for reconstruction. In addition, selection procedures should be developed that balance the requirements of speed and expertise.

\section{Barriers to Enhancing Resilience}

Moving forward on the foregoing agenda faces some well-defined barriers. In this section, we identify some of the main inhibitors to an enhancing of resilience capacities. The various inhibitors are found in the areas of organisational preparedness (Pauchant and Mitroff, 1992), governance and society. It appears that Western societies have a number of inherent constraints to a resilient approach to catastrophic breakdowns.

- Individual defence mechanisms. People's responses to potential future threats typically encompass a range of dysfunctions (e.g. denial, downgrading threat importance, impotence). Both political leaders and individual citizens can be susceptible to maladaptive thinking in the face of the 'worst' that might happen. It has proven incredibly hard to break through these mental barriers.

- Organisational beliefs and rationalisations. Most organisations (public agencies, political decision making authorities, NGOs and private companies) are imbued with cultural values that predominate over matters of resilience. Critical failures tend to rank much lower than values of service provision, efficiency, and profit margins. When challenged by critical events elsewhere, organisations have a tendency towards 'rationalising' - towards interpreting potential threats in an 'inside the box' manner, which suggests that 'it cannot happen here' and that 'we can deal with these events'.

- Institutional designs for crisis management. Most organisations are not designed to cope with critical breakdowns. Despite the fact that there is growing evidence that preparedness for critical breakdowns requires rapid and flexible decision making authority, organisational structures are typically rooted in shifting authority upwards. Rapid redivisions of labour in accordance with situational imperatives clashes with cultural imperatives. 
- Costs of preparation. Robust contingency planning for breakdowns is not a 'mission impossible' but it is certainly very difficult (McConnell and Drennan, 2006). Promoting resilient systems requires (i) investing time and resources in plans that may never need to be activated (ii) cooperating in a 'joined up' way with multiple stakeholders, who have their own mandates, priorities, legal status, decision making cycles, communications systems, information capacities and cultures, and (iii) simulations, exercises and training. All this takes time and money, with no visible outputs (an 'avoided crisis' does not show up in the books).

- Governance frameworks. During times of crisis and breakdown, leaders would be expected to lead. Preparations are not complete without a plan that guarantees the working of a command and control model. Reassuring as it may be, such preparations are of limited use. However, it is hard to change this inclination towards top-down structures. To invest in resilience - with its emphasis on self-reliance and improvisation - is a hard sell for politicians.

- Socio-economic frameworks. It is hard to expect communities to be resilient when many of them are already in disarray. The modern mega-city houses the most vulnerable people: poor, homeless, criminals, mentally ill, addicts, the sick, immigrants - in short the people who have the least resilience. The city is fractured, anonymous and hard to manage in normal times. The civil unrest in New Orleans after the breakdown of networks after Hurricane Katrina suggest that expecting resilience in times of major adversity may simply be a bridge too far.

\section{Conclusion: What Future for Resilience?}

Promoting resilience strategies in preparation for $\mathrm{Cl}$ breakdowns is a tough call. It competes against individual, institutional and societal vulnerabilities and priorities. Citizens are pre-occupied with their routine and often troubled lives; organisations are focused on dayto-day priorities and longer terms goals (bigger, faster, better, more efficient), and political leaders are preoccupied with the vagaries of elections, party politics, media battles, and policy making. The call for resilience may thus seem to many a future priority at best.

Conditions for enhanced resilience capacities thus seem most likely to emerge on the crest of catastrophes. Crises and disasters do not guarantee change and learning (Birkland, 1997; Boin, McConnell and ' $t$ Hart, 2006) but they are one of the few ways in which established policies, procedures, cultures and legitimacies change course (Baumgartner and Jones, 1993). The question - perhaps a rhetorical one - is whether we can afford to wait that long. If we accept that terrorism, technological development, and climate changes can have catastrophic consequences (a staple of crisis research thinking), we must consider what can be done to enhance societal resilience.

In the absence of catastrophic breakdowns, the academic community can pursue three courses of action that may benefit societal resilience. First, they can formulate credible scenarios that explain how seemingly small errors can cascade into breakdowns that quickly defy existing defence mechanisms (Schwartz, 2003). Many worst-case scenarios fail to convince and invite ridicule on the part of practitioners. To this end, we need detailed studies of catastrophic breakdowns and successful ways of 'islanding' emerging breakdowns. The high reliability school of thinking (JCCM, 1996) provides useful stepping stones, as do engineering approaches (Petroski, 1992; Baer et al., 2005). Finally, academics must publicly confront overly optimistic accounts of prevention and preparedness. It must become widely understood that government cannot prepare for each and every contingency. When the worst happens, a different governmental mode is required. In this article, we have offered some building blocks for such an approach.

\section{Acknowledgements}

Earlier versions of this article were presented at two conferences: 'Managing Extreme Events: Transatlantic Perspectives', University of Pittsburgh, 3-4 March 2006 and 'Future Challenges for Crisis Management in Europe', Swedish Emergency Management Agency and European Crisis Management Academy, Stockholm, 4-5 May 2006. We thank the participants of these seminars, as well as Paul 't Hart and Werner Overdijk for their helpful comments.

\section{Notes}

I. The US federal government categorises $\mathrm{Cl}$ sectors as: agriculture, food, water, public health, emergency services, government, defense industrial base, information and telecommunications, energy, transportation, banking and finance, chemicals and hazardous materials, postal services and shipping.

2. A degree of normalisation could be obtained through the publication of regular community risk assessments. Although such a move would be controversial and subject to critical media and citizen scrutiny, it would increase awareness and debates around community risks.

\section{References}

Altheide, D.L. (2002), Creating Fear: News and the Construction of Crisis, Aldine De Gruyter, Hawthorne, NY. 
Anheier, H.K. (Ed.) (1999), When Things Go Wrong: Organizational Failures and Breakdowns, Sage, Thousand Oaks, CA.

Baumgartner, F.R. and Jones, B.D. (1993), Agendas and Instability in American Politics, University of Chicago Press, Chicago.

Baer, M., Heron, K., Morton, O. and Ratliff, E. (2005), Safe: The Race to Protect Ourselves in a Newly Dangerous World, HarperCollins Publishers, New York.

Barton, A.H. (1969), Communities in Disaster: A Sociological Analysis of Collective Stress Situations, Doubleday, New York.

Beck, M., Asenova, D. and Dickson, G. (2005), 'Public Administration, Science and Risk Assessment: A Case Study of the UK Bovine Spongiform Encephalopathy Crisis', Public Administration Review, Volume 65, Number 4, pp. 396-408.

Birkland, T.A. (1997), After Disaster: Agenda Setting, Public Policy, and Focusing Events, Georgetown University Press, Washington, DC.

Boin, R.A. (2005), 'From Crisis to Disaster: Toward an Integrative Perspective', in Perry, R. and Quarantelli, E.L. (Eds), What is a Disaster? New Answers to Old Questions, Xlibris Press, Philadelphia, Pp. 153-172.

Boin, A. and Smith, D. (2006), 'Terrorism and Critical Infrastructures: Implications for Public-Private Crisis Management', Public Money \& Management, Volume 26, Number 5, pp. 295-304.

Boin, R.A., Kofman-Bos, C. and Overdijk, W.I.E. (2004), 'Crisis Simulations: Exploring Tomorrow's Vulnerabilities and Threats', Simulation and Gaming: An International Journal of Theory, Practice and Research, Volume 35, Number 3, Pp. 378-393.

Boin, A., McConnell, A. and 't Hart, P. (2006), 'Inertia or Change? Crisis-induced Challenges for Political Leaders', Refereed paper presented to the Australasian Political Studies Association Conference, University of Newcastle 25-27 September, URL: http://www.newcastle.edu.au/ school/ept/politics/apsa/abs.publicpolicy.html.

Boin, A., 't Hart, P., Stern, E. and Sundelius, B. (2005), The Politics of Crisis Management: Public Leadership Under Pressure, Cambridge University Press, Cambridge.

Clarke, L. (1999), Mission Improbable: Using Fantasy Documents to Tame Disaster, University of Chicago Press, Chicago.

Clarke, L. (2005), Worst Cases: Terror and Catastrophe in the Popular Imagination, University of Chicago Press, Chicago.

Coles, E. and Buckle, P. (2004), 'Developing Community Resilience as a Foundation for Effective Disaster Recovery', Australian Journal of Emergency Management, Volume 19, Number 4, pp. 6-15.

Comfort, L.K. (Ed.) (1988), Managing Disaster: Strategies and Policy Perspectives, Duke University Press, Durham.

Coombs, W.T. (1999), Ongoing Crisis Communication: Planning, Managing and Responding, Sage, Thousand Oaks, CA.

Cornall, R. (2005), 'New Levels of Government Responsiveness for 'All Hazards': The Management of Natural Disasters and Emergencies', Australian Journal of Public Administration, Volume 64, Number 2, Pp. 27-30.

Curtin, T., Hayman, D. and Husein, N. (2005), Managing Crisis: A Practical Guide, Palgrave Macmillan, Basingstoke.

Drennan, L.T. and McConnell, A. (2007 forthcoming), Risk and Crisis Management in the Public Sector, Routledge, Abingdon.
Drabek, T.E. (1986), Human System Responses to Disaster: An Inventory of Sociological Findings, Springer, New York.

Dynes, R.R. (1970), Organized Behaviour in Disaster, Heath and Company, Lexington, DC.

Dyson, M.E. (2006), Come Hell or High Water: Hurricane Katrina and the Color of Disaster, Basic Books, New York.

Egan, M.J. (2007), 'Anticipating Future Vulnerability: Defining Characteristics of Increasingly Critical Infrastructure-like Systems', Journal of Contingencies and Crisis Management, Volume I5, Number I, pp. 4-I7.

Fink, S. (2002), Crisis Management: Planning for the Inevitable, iUniverse, Lincoln, NE.

Flin, R. (1996), Sitting in the Hot Seat: Leaders and Teams for Critical Incident Management, John Wiley \& Sons, New York.

Gauld, R. and Goldfinch, S. (2006), Dangerous Enthusiasms: E-government, Computer Failure and Information System Development, Otago University Press, Otago.

Healy, S. (200I), 'Privileging Process Over "Fact": The Sydney Water Scare as "Organised Irresponsibility", Science and Public Policy, Volume 28, Number 2, Pp. 123-129.

Hermann, M.G., Preston, T., Korany, B. and Shaw, T.M. (200I), 'Who Leads Matters: The Effects of Powerful Individuals', International Studies Review, Volume 3, Number 2, pp. 83-131.

Hillyard, M.J. (2000), Public Crisis Management: How and Why Organizations Work Together to Solve Societies Most Threatening Problems, Writers Club Press, Lincoln, NE.

Journal of Contingencies and Crisis Management (1994), Volume 2, Number 4.

Journal of Contingencies and Crisis Management (1996), Volume 4, Number 2.

Lagadec, P. and Bertone, L. (2003), Voyage au Coeur d'une Implosion: Ce Que l'Argentine Nous Apprehend, Eyrolles, Paris.

LaPorte, T.R. (1996), 'High Reliability Organizations: Unlikely, Demanding, and at Risk', Journal of Contingencies and Crisis Management, Volume 4, Number 2, Pp. 60-7I.

Longstaff, P.H. (2005), 'Security, Resilience and Communication in Unpredictable Environments such as Terrorism, Natural Disasters and Complex Technology', Program on Information Resources Policy, Center for Information Policy Research, Harvard University, URL: http://www.pirp. harvard.edu.

McConnell, A. (2003), 'Overview: Crisis Management, Influences, Responses and Evaluation', Parliamentary Affairs, Volume 56, Number 3, pp. 393-409.

McConnell, A. (2005), 'Post-Crisis Reform and Learning in the Aftermath of the 1998 Sydney Water Crisis', Report Number: GOV2005-4, Sydney University: School of Economics and Political Science, URL: http://www.econ.usyd. edu.au//3602.html.

McConnell, A. and Drennan, L. (2006), 'Mission Impossible? Planning and Preparing for Crisis', Journal of Contingencies and Crisis Management, Volume 14, Number 2, pp. 59-70.

National Commission on Terrorist Attacks Upon the United States (2004), The 9/I I Commission Report: Final Report of the National Commission on Terrorist Attacks Upon the United States, W.W. Norton, New York.

Newlove, L.M., Stern, E.K. and Svedin, L. (2000), Auckland Unplugged, Crismart, Stockholm. 
Nudell, M. and Antokol, N. (1988), The Handbook for Effective Emergency and Crisis Management, Lexington Books, Lexington.

OECD (2003), Emerging Risks in the 2 I st Century: An Agenda for Action, OECD, Paris.

Pauchant, T.C. and Mitroff, I.I. (1992), Transforming the CrisisProne Organization: Preventing Individual, Organizational and Environmental Tragedies, Jossey-Bass, San Francisco.

Paul, L. (2005), 'New Levels of Responsiveness - Joining Up Government in Response to the Bali Bombings', Australian Journal of Public Administration, Volume 64, Number 2, pp. $31-33$.

Parker, C.F., Stern, E.K. and Paglia, E. (2006), 'When the Levee Breaks: The Origins of the Hurricane Katrina Response Failure', Paper presented at the workshop 'Protecting Critical Infrastructures: Vulnerable Systems, Modern Crises, and Institutional Design', Conference on Future Challenges for Crisis Management in Europe, Stockholm, 4-5 May.

Perrow, C. (1999), Normal Accidents: Living with High-Risk Technologies, 2nd Edition, Princeton University Press, Princeton.

Perrow, C. (2006), 'Disasters Ever More? Reducing U.S. Vulnerabilities', in Rodriguez, H., Quarantelli, E.L. and Dynes, R.R. (Eds), Handbook of Disaster Research, Springer, New York, Pp. 52I-533.

Perry, R.W. and Lindell, M.K. (2006), Emergency Planning, John Wiley \& Sons, Hoboken, NJ.

Perry, R.W. and Quarantelli, E.L. (Eds) (2005), What is a Disaster? New Answers to Old Questions, Xlibris, Philadelphia.

Petroski, H. (1992), To Engineer is Human: The Role of Failure in Successful Design, Vintage Books, New York.

Phillips Inquiry (2000), 'The BSE Inquiry: The Report', URL: http://www.bseinquiry.gov.uk/report/index.htm.

Posner, R.A. (2004), Catastrophe: Risk and Response, Oxford University Press, Oxford.

Post, J.M. (2004), Leaders and Their Followers in a Dangerous World: The Psychology of Political Behaviour, Cornell University Press, Ithaca.

Quarantelli, E.L., Lagadec, P. and Boin, A. (2006), 'A Heuristic Approach to Future Disasters and Crisis: New, Old, and In-Between Types', in Rodriguez, H., Quarantelli, E.L. and Dynes, R. (Eds), Handbook of Disaster Research, Springer, New York, Pp. 16-4I.

Reason, J. (1990), Human Error, Cambridge University Press, Cambridge.

Reason, J. (1997), Managing the Risks of Organizational Accidents, Ashgate, Aldershot.

Regster, M. and Larkin, J. (2002), Risk Issues and Crisis Management: A Casebook of Best Practice, 2nd Edition, Kogan Page, London.
Rijpma, J.A. (1997), 'Complexity, Tight-Coupling and Reliability: Connecting Normal Accidents Theory and High Reliability Theory', Journal of Contingencies and Crisis Management, Volume 5, Number I, PP. I5-23.

Rosenthal, U. and Pijnenberg, B. (Eds) (1991), Crisis Management and Decision Making: Simulation Oriented Scenarios, Kluwer, Dordrecht.

Rosenthal, U., 't Hart, P. and Kouzmin, A. (199I), 'The Bureau-Politics of Crisis Management', Public Administration, Volume 69, Number 2, Pp. 21I-233.

Rosenthal, U., Boin, R.A. and Comfort, L.K. (200I), 'The Changing World of Crisis and Crisis Management', in Rosenthal, U., Boin, R.A. and Comfort, L.K. (Eds), Managing Crises: Threats, Dilemmas and Opportunities, Charles C. Thomas, Springfield, pp. 5-27.

Sabato, L.J. (2000), Feeding Frenzy: Attack Journalism and American Politics, Lanahan, Baltimore.

Scanlon, J. (1999), 'Emergency Groups in Established Frameworks: Ottawa Carleton's Response to the 1998 Ice Disaster', Journal of Contingencies and Crisis Management, Volume 7, Number I, pp. 30-27.

Schwartz, P. (2003), Inevitable Surprises: Thinking Ahead in a Time of Turbulence, Gotham Books, New York.

Select Bipartisan Committee to Investigate the Preparation for and Response to Hurricane Katrina (2006), Failure of Initiative: The Final Report of the Select Bipartisan Committee to Investigate the Preparation for and Response to Hurricane Katrina, The US House of Representatives, URL: http:// katrina.house.gov/full_katrina_report.htm.

't Hart, P. (1993), 'Symbols, Rituals and Power: The Lost Dimension in Crisis Management', Journal of Contingencies and Crisis Management, Volume I, Number I, Pp. 36-50.

't Hart, P. (1997), 'Preparing Policy Makers for Crisis Management: The Role of Simulations', Journal of Contingencies and Crisis Management, Volume 5, Number 4, pp. 207-2I5.

't Hart, P., Rosenthal, U. and Kouzmin, A. (1993), 'Crisis Decision Making: The Centralization Thesis Revisited', Administration and Society, Volume 25, Number I, Pp. I2-45.

Tierney, K.J. (2006), 'Businesses and Disasters: Vulnerability, Impacts and Recovery', in Rodriguez, H., Quarantelli, E.L. and Dynes, R.R. (Eds), Handbook of Disaster Research, Springer, New York, pp. 275-296.

Turner, B.A. (1978), Man-made Disasters, Wykeham, London.

Weick, K.E. and Sutcliffe, K.M. (2002), Managing the Unexpected: Assuring High Performance in an Age of Complexity, Jossey-Bass, San Francisco.

Wildavsky, A. (1988), Searching for Safety, Transaction, New Brunswick. 